\title{
Serological Predictors for the Recurrence of Atrial Fibrillation After Electrical Cardioversion
}

\author{
Sook Kyoung Kim, MSc ${ }^{1}$, Hui-Nam Pak, MD ${ }^{1}$, Jae Hyung Park, BSc ${ }^{1}$, Kyoung Jeong Ko, RN ${ }^{2}$, \\ Jihei Sara Lee, $\mathrm{BSc}^{2}$, Jin Wi, MD${ }^{1}$, Jong Il Choi, $\mathrm{MD}^{2}$ and Young-Hoon Kim, MD² \\ ${ }^{l}$ Yonsei University Health System, Seoul, ${ }^{2}$ Korea University Cardiovascular Center, Seoul, Korea
}

\begin{abstract}
Background and Objectives: Although electrical cardioversion $(\mathrm{CV})$ is effective in restoring sinus rhythm (SR) in patients with atrial fibrillation (AF), AF frequently recurs in spite of antiarrhythmic medications. We investigated the predictors of failed CV and AF recurrence after successful CV. Subjects and Methods: In 81 patients (M:F= 63:18, 59.1 \pm 10.5 years old) with AF who underwent CV, clinical findings and pre-CV serologic markers were evaluated. Results: During 13.1 \pm 10.6 months of follow-up, 8.6\% (7/81) showed failed CV, 27.16\% (22/81) showed early recurrence atrial fibrillation (ERAF; $\leq 2$ weeks), 32.1\% (26/81) had late recurrence atrial fibrillation (LRAF; > 2 weeks), and 32.1\% (26/81) remained in SR and had no recurrence (NR). Plasma levels of transforming growth factor beta (TGF)- $\beta$ were significantly higher in patients with failed CV than in those with successful CV $(p=0.0260)$. Patients in whom AF recurred were older $(60.4 \pm 9.0$ years old vs. $55.3 \pm 12.5$ years old, $p=0.0220)$, and had lower plasma levels of stromal cell derived factor (SDF)-1 $\alpha(\mathrm{p}=0.0105)$. However, there were no significant differences in these parameters between ERAF patients and LRAF patients. Conclusion: Post-CV recurrence commonly occurs in patients aged $>60$ years and who have low plasma levels of SDF- $1 \alpha$. High plasma levels of TGF- $\beta$ predict failure of electrical CV. (Korean Circ J 2010;40:185-190)
\end{abstract}

KEY WORDS: Atrial fibrillation; Electric countershock; Recurrence.

\section{Introduction}

Atrial fibrillation (AF) is the most common cardiac arrhythmia in clinical practice. It leads to significant morbidity and disability and results in a low quality of life. ${ }^{1)}$ It has been reported that appropriate rhythm control may reduce mortality in patients with $\mathrm{AF}^{2)}$ Although electrical cardioversion (CV) is known to be effective in restoring sinus rhythm (SR) in patients with persistent AF (PeAF), AF frequently recurs in spite of concomitant medication with antiarrhythmic drugs. ${ }^{34)}$ Approximately $50 \%$ of patients who successfully cardio-

Received: August 8, 2009

Revision Received: September 17, 2009

Accepted: October 20, 2009

Correspondence: Hui-Nam Pak, MD, Yonsei University Health System, 250 Seongsan-ro, Seodaemun-gu, Seoul 120-752, Korea

Tel: 82-2-2228-8459, Fax: 82-2-393-2041

E-mail: hnpak@yuhs.ac

(c) This is an Open Access article distributed under the terms of the Creative Commons Attribution Non-Commercial License (http://creativecommons. org/licenses/by-nc/3.0) which permits unrestricted non-commercial use, distribution, and reproduction in any medium, provided the original work is properly cited. vert initially experience $A F$ recurrence within the first month after CV. ${ }^{5) 6}$ This is due to significant electrical remodeling, ${ }^{7) 8)}$ structural changes in the atrial myocardium in patients with $\mathrm{AF}^{9)}$ and the limitations of antiarrhythmic drugs. ${ }^{23) 5)}$ Although there have been several reports, ${ }^{1112)}$ the predictors of successful CV or long-term maintenance of SR in patients with PeAF are not yet clear. The development of serological predictors for recurrence after CV may reduce the number of unnecessary procedures, the risk of complications and medical costs, and may improve the clinical outcome of highly selected patients. Discovering predictors for post-CV recurrence would also contribute to our understanding of AF pathophysiology. Therefore, we investigated whether certain parameters related to matrix remodeling, fibrosis, atrial stretching, and chemotaxis, can predict failure or recurrence of AF after electrical CV.

\section{Subjects and Methods}

\section{Study population}

This study was approved by the Institutional Review Board of Anam Hospital of Korea University. All patients 
provided written informed consent. Eighty-one patients with PeAF (male:female $=63: 18$, mean age 59.1 \pm 10.5 years old) who underwent external electrical CV were included in the study. We excluded patients with a history of any previous $\mathrm{CV}$, significant mitral valvular heart disease, a huge left atrium (LA; $>55 \mathrm{~mm}$ ), a recent infection, surgery or acute coronary syndrome in the 2 months prior to the collection of blood samples. All patients maintained optimal anticoagulation, had been taking anti-arrhythmic drugs for at least 1 month, and maintained them after CV. Transesophageal echocardiography was done to exclude an intra-cardiac thrombus on the same day of CV in every patient. The blood samples for the serologic assays were drawn before sedation for external CV.

\section{Electrical cardioversion protocol}

After obtaining written informed consent, electrical $\mathrm{CV}$ was performed under sedation with intravenous midazolam $(0.05 \mathrm{mg} / \mathrm{kg})$ and thiopental sodium (60 $\mathrm{mg} / \mathrm{kg}$ ). A biphasic R wave synchronized shock (Lifepak12, Physiocontrol Ltd. Redmond, WA, USA) was applied to the patients via self-adhesive skin electrodes (TZ Medical Inc., Portland, OR, USA) in an anteriorposterior position. We delivered an initial CV with $70 \mathrm{~J}$. If the initial shock failed to terminate $\mathrm{AF}$, the biphasic shock energy was gradually increased to $100 \mathrm{~J}, 150 \mathrm{~J}$, and then $200 \mathrm{~J}$ serially ( 5 minutes intervals). If CV terminated AF successfully, the patient's cardiac rhythm was monitored for 15 minutes to detect an atrial premature beat (APC) or recurrence of AF. If AF returned within 15 minutes of termination of $\mathrm{CV}$, amiodarone $150 \mathrm{mg}$ was administered intravenously and the same energy shock was repeated. Patients in whom AF remained even after being given a $200 \mathrm{~J} \mathrm{CV}$ or who exhibited repeated immediate recurrence of AF in spite of amiodarone were defined as failed CVs.

\section{Biochemical analyses}

We acquired a $5 \mathrm{~mL}$ sample of peripheral blood immediately before CV to measure the plasma levels of several protein markers or chemokines by enzyme linked immuno-sorbent assay: pro-atrial natriuretic peptide (ANP; Biomedica, Antony, France), matrix metalloproteinase (MMP)-9, transforming growth factor (TGF)- $\beta$, and stromal cell derived factor (SDF)- $1 \alpha$ (R\&D Systems, Minneapolis, MN, USA). High sensitivity C-reactive protein (hs-CRP) was measured on a Hitachi 912 assay system (Roche Diagnostics, Indianapolis, IN, USA) using a Kamiya K-assay (Kamiya Biomedical Corp., Seattle, WA), which quantitatively determines CRP by a latex particle-enhanced immuno-turbidimetric assay.

\section{Follow-up of patients}

After CV, all patients were prospectively followed up at an outpatient clinic at 1, 2, 4, 8 weeks, and then every 3 months thereafter. Elecrocardiography (ECG) was performed at every visit or anytime the patient reported palpitations. A Holter ECG (24 hours or 48 hours) and/or event recorder was evaluated at 2 months in patients who did not experience recurrence. We classified patients into 4 different groups according to clinical outcome as follows: 1) failed CV, 2) early recurrence of AF (ERAF; within 2 weeks), 3) late recurrence of AF (LRAF; after 2 weeks), and 4) no recurrence (NR) after 2 months.

\section{Statistical analysis}

We evaluated the clinical factors \{e.g., age, sex, LA size, ejection fraction $(\mathrm{EF})$, spontaneous echo contrast (SEC)\} and serologic factors (MMP-9, SDF- $1 \alpha$, TGF- $\beta$, proANP, and hs-CRP) in terms of success or failure of CV and the timing of recurrence. Comparisons between groups were analyzed by the Mann-Whitney test or a t-test. In order to identify the predictors of failed CV or the recurrence of AF after successful CV, uni-variate and multivariate logistic regression analyses were performed. AF free rates were compared in terms of clinical, electrophysiological, and serological parameters by utilizing KaplanMeier curves. We chose cutoff numbers that were similar to the mean that divided 2 groups with similar numbers of the patients. All values are expressed as mean \pm SD. All statistical analyses were performed using Statistical Package for the Social Sciences (SPSS) version 12.0 and a $\mathrm{p}<0.05$ was considered statistically significant.

\section{Results}

\section{Patient characteristics and clinical outcomes}

We performed external electrical $\mathrm{CV}$ in 81 patients (59.1 \pm 10.5 years old, 63 males) with PeAF or permanent AF. The mean LA size was $45.5 \pm 6.0 \mathrm{~mm}$, and the mean EF of the LV was $48.7 \pm 15.1 \%$. All patients had been taking antiarrhythmic drugs for at least 1 month before and after CV (amiodarone 60.5\%, other class IC anti-arrhythmic drugs $39.5 \%$ ). The mean number of electrical shocks performed was $1.9 \pm 1.4$, the final successful CV energy was $96.7 \pm 32.3 \mathrm{~J}$, and the cumulative CV energy was $170.4 \pm 178.5 \mathrm{~J}$. Among the 81 patients, $8.6 \%$ (7/81) showed failed CV and $91.4 \%$ (74/81) underwent successful CV. We followed up the 74 patients after their successful CV for an average of $13.2 \pm 11.0$ months. Of the 74, $22(29.7 \%)$ showed AF recurrence within 2 weeks (ERAF), 26 (35.1\%) after 2 weeks (LRAF), and 26 (35.1\%) remained in SR and had NR during the follow-up period.

\section{Serological predictors for failed electrical cardioversion}

Table 1 summarizes comparisons of the clinical and 
Table 1. Comparison of patients with failed CV and successful CV

\begin{tabular}{lccc}
\hline & $\begin{array}{c}\text { Failed CV } \\
(\mathrm{n}=7)\end{array}$ & $\begin{array}{c}\text { Successful CV } \\
(\mathrm{n}=74)\end{array}$ & $\mathrm{p}$ \\
\hline Male (\%) & 85.71 & 77.03 & 0.3013 \\
Age (years) & $63.71 \pm 8.50$ & $58.62 \pm 10.58$ & 0.1104 \\
LA size (mm) & $42.53 \pm 6.90$ & $45.76 \pm 5.90$ & 0.1037 \\
EF (\%) & $44.73 \pm 24.36$ & $49.13 \pm 14.12$ & 0.2326 \\
SEC (\%) & 50.00 & 58.33 & 0.3480 \\
Amiodarone (\%) & 28.6 & 64.9 & 0.0301 \\
J final & $121.4 \pm 26.7$ & $93.73 \pm 31.83$ & 0.0154 \\
IRAF (\%) & 71.43 & 4.05 & $<0.0001$ \\
IV AAD (\%) & 100.00 & 14.86 & $<0.0001$ \\
APC $(\%)$ & 28.57 & 56.16 & 0.0830 \\
Bradycardia (\%) & 0.00 & 4.29 & 0.2911 \\
MMP-9 $(\mathrm{ng} / \mathrm{mL})$ & $89.77 \pm 41.27$ & $123.13 \pm 62.80$ & 0.0882 \\
SDF-1 $\alpha(\mathrm{ng} / \mathrm{mL})$ & $3.64 \pm 1.09$ & $3.47 \pm 1.14$ & 0.3519 \\
TGF- $\beta(\mathrm{ng} / \mathrm{mL})$ & $22.68 \pm 22.92$ & $13.48 \pm 9.84$ & 0.0260 \\
Pro-ANP $(\mathrm{nmol} / \mathrm{L})$ & $6.62 \pm 3.56$ & $5.54 \pm 4.32$ & 0.2624 \\
hs-CRP $(\mathrm{ng} / \mathrm{mL})$ & $3.68 \pm 6.21$ & $4.18 \pm 11.71$ & 0.4559 \\
Recurrence $(\%)$ & 100.00 & 64.38 & 0.0380 \\
\hline
\end{tabular}

CV: cardioversion, LA: left atrium, EF: ejection fraction, SEC: spontaneous echo contrast, J final: final CV energy (J), IRAF: immediate recurrence of $\mathrm{AF}$ after $\mathrm{CV}, \mathrm{AAD}$ : anti-arrhythmic drug, $\mathrm{APC}$ : atrial premature contractions, MMP-9: matrix metalloproteinase-9, SDF- $1 \alpha$ : stromal cell derived factor- $1 \alpha$, TGF- $\beta$ : transforming growth factor- $\beta$, ANP: atrial natriuretic peptide, hsCRP: high sensitive-C reactive protein, $\mathrm{AF}$ : atrial fibrillation

biochemical parameters in patients with successful and failed electrical CV. There were no significant differences in age, sex, LA size, EF, the existence of SEC, or medications. However, the prescription rate of amiodarone was lower in patients with failed CV compared to those with successful CV (28.6\% vs. $64.9 \%, p=0.0301)$. Both the final energy $(121.4 \pm 26.7 \mathrm{~J}$ vs. $93.7 \pm 31.8 \mathrm{~J}, \mathrm{p}=0.0154)$ and the incidence of the requirement of intravenous amiodarone $(100 \%$ vs. $14.9 \%, \mathrm{p}<0.0001)$ were higher in patients with failed CV. The pre-CV plasma level of TGF- $\beta$, which reflects the degree of fibrosis, was significantly higher in patients with failed CV $(22.7 \pm 22.9$ $\mathrm{ng} / \mathrm{mL})$ than in those with successful CV (13.5 \pm 9.8 $\mathrm{ng} / \mathrm{mL}, \mathrm{p}=0.0260$ ).

\section{Predictors for recurrence after successful cardioversion}

The recurrence rate of AF after successful $\mathrm{CV}$ was $64.9 \%(48 / 74)$ during the $13.2 \pm 11.0$ months followup. Table 2 summarizes comparisons of clinical, electrophysiological, and serological parameters. The patients who showed recurring $\mathrm{AF}$ after $\mathrm{CV}$ were older than those without recurrence $(60.4 \pm 9.0$ years old vs. $55.3 \pm 12.5$ years old, $p=0.0220$ ). There was no significant difference in either LA size or EF. Pre-CV plasma levels of SDF- $1 \alpha(3.2 \pm 1.2 \mathrm{ng} / \mathrm{mL}$ vs. $3.9 \pm 0.8 \mathrm{ng} / \mathrm{mL}, \mathrm{p}=$ $0.0105)$ were significantly lower in patients with recur-
Table 2. Comparison of patients with recurrence of $A F$ and no recurrence of $\mathrm{AF}$ after successful $\mathrm{CV}$

\begin{tabular}{lccc}
\hline & $\begin{array}{c}\text { Recurrence } \\
(\mathrm{n}=48)\end{array}$ & $\begin{array}{c}\text { No recurrence } \\
(\mathrm{n}=26)\end{array}$ & $\mathrm{p}$ \\
\hline Male (\%) & 81.25 & 69.23 & 0.1233 \\
Age (years) & $60.44 \pm 8.99$ & $55.27 \pm 12.52$ & 0.0220 \\
LA size (mm) & $46.15 \pm 5.08$ & $45.05 \pm 6.63$ & 0.2286 \\
EF (\%) & $48.93 \pm 14.51$ & $49.50 \pm 13.67$ & 0.4346 \\
SEC (\%) & 68.1 & 40.0 & 0.0106 \\
Amiodarone (\%) & 66.7 & 61.5 & 0.3321 \\
J final (J) & $91.95 \pm 30.10$ & $97.78 \pm 36.06$ & 0.2617 \\
IRAF (\%) & 6.25 & 0.00 & 0.0991 \\
IV AAD (\%) & 12.50 & 19.23 & 0.2220 \\
APC (\%) & 59.57 & 50.0 & 0.2184 \\
Bradycardia (\%) & 6.67 & 0.00 & 0.0961 \\
MMP-9 (ng/mL) & $124.28 \pm 75.80$ & $121.58 \pm 40.60$ & 0.4348 \\
SDF-1 $\alpha(\mathrm{ng} / \mathrm{mL})$ & $3.242 \pm 1.24$ & $3.88 \pm 0.80$ & 0.0105 \\
TGF- $\beta(\mathrm{ng} / \mathrm{mL})$ & $13.38 \pm 8.15$ & $13.61 \pm 11.93$ & 0.4652 \\
Pro-ANP (nmol/L) & $4.92 \pm 4.36$ & $6.68 \pm 4.09$ & 0.0477 \\
hs-CRP (ng/mL) & $4.29 \pm 11.20$ & $4.01 \pm 12.68$ & 0.4616 \\
Time to recurrence & $51.17 \pm 106.58$ & $0.00 \pm 0.00$ & 0.0086 \\
(days) & &
\end{tabular}

AF: atrial fibrillation, CV: cardioversion, LA: left atrium, EF: ejection fraction, SEC: spontaneous echo contrast, J final: final CV energy (J), IRAF: immediate recurrence of AF after CV, AAD: anti-arrhythmic drug, APC: atrial premature contractions, MMP-9: matrix metalloproteinase-9, SDF- $1 \alpha$ : stromal cell derived factor- $1 \alpha$, TGF$\beta$ : transforming growth factor- $\beta$, ANP: atrial natriuretic peptide, hs-CRP: high sensitive- $C$ reactive protein

rent AF than in those without recurrence. In univariate logistic regression analyses, it was found that old age \{odds ratio (OR) 1.053, 95\% confidence interval (CI) 1.004-1.053, $\mathrm{p}=0.035\}$ and lower SDF- $1 \alpha$ (OR 0.603, $95 \%$ CI $0.379-0.960, p=0.033)$ may predict the recurrence of $\mathrm{AF}$ after successful CV. In multivariate logistic regression analysis, low SDF- $1 \alpha$ (OR 0.537, 95\% CI $0.302-0.954, p=0.034)$ was an independent risk factor for AF recurrence after successful CV. In Kaplan-Meier analyses, the AF recurrence rate was higher in patients who were older than $60(\mathrm{p}=0.0295)$ and had plasma SDF-1 $\alpha<3.0 \mathrm{ng} / \mathrm{mL}$ (p=0.0114) (Fig. 1).

\section{Timing of recurrence}

Among 48 patients whose AF recurred during the follow-up period after successful CV, 45.8\% (22/48) recurred within 2 weeks (ERAF), while 54.2\% (26/48) recurred after 2 weeks (LRAF) (Table 3). The mean time to LRAF was $85.5 \pm 134.7$ days. However, we failed to find a significant difference in clinical and serological parameters between ERAF and LRAF groups (Table 3).

\section{Left atrium size dependent factors}

We compared patients with LA $\geq 45 \mathrm{~mm}$ to those with LA $<45 \mathrm{~mm}$. In patients with LA $\geq 45 \mathrm{~mm}$, the incidence of SEC $(69.8 \%$ vs. $45.5 \%, p=0.0164)$ was higher. However, the failure rate of $\mathrm{CV}$ and the recurr- 

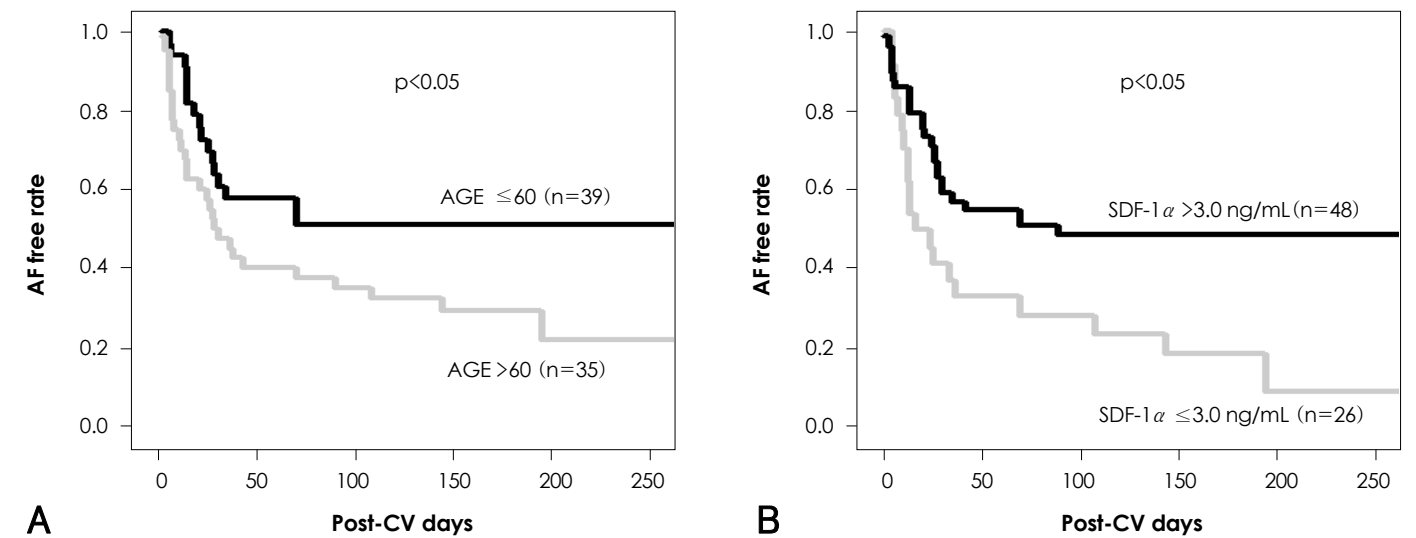

Fig. 1. Kaplan-Meier curves suggest a higher recurrence rate of $A F$ after successful $C V$ in patients aged $>60$ years $(A)$ and $S D F-1 \alpha \leq 3.0$ $\mathrm{ng} / \mathrm{mL}$ (B). AF: atrial fibrillation, CV: cardioversion.

Table 3. Comparison of patients in whom AF recurred within 2 weeks or after 2 weeks of successful CV

\begin{tabular}{lccc}
\hline & $\begin{array}{c}\text { ERAF } \\
(\leq 2 \text { weeks }) \\
(\mathrm{n}=22)\end{array}$ & $\begin{array}{c}\text { LRAF } \\
(>2 \text { weeks }) \\
(\mathrm{n}=26)\end{array}$ & $\mathrm{p}$ \\
\hline Male $(\%)$ & 81.0 & 81.0 & 0.4938 \\
Age (years) & $62.82 \pm 9.86$ & $59.27 \pm 8.20$ & 0.1666 \\
LA size (mm) & $46.77 \pm 4.40$ & $45.68 \pm 6.27$ & 0.2571 \\
EF mean $(\%)$ & $48.07 \pm 13.62$ & $49.62 \pm 15.43$ & 0.3606 \\
SEC (\%) & 63.64 & 72.0 & 0.2748 \\
J final $(\mathrm{J})$ & $96.50 \pm 34.68$ & $85.0 \pm 27.39$ & 0.1190 \\
IRAF $(\%)$ & 4.54 & 7.70 & 0.3309 \\
IV AAD $(\%)$ & 13.64 & 11.54 & 0.4156 \\
APC $(\%)$ & 68.19 & 52.00 & 0.1345 \\
Bradycardia $(\%)$ & 4.76 & 8.33 & 0.3205 \\
MMP-9 $(\mathrm{ng} / \mathrm{mL})$ & $109.84 \pm 73.19$ & $137.92 \pm 77.74$ & 0.1399 \\
SDF-1 $\alpha(\mathrm{ng} / \mathrm{mL})$ & $3.25 \pm 1.31$ & $3.24 \pm 1.21$ & 0.4871 \\
TGF- $\beta(\mathrm{ng} / \mathrm{mL})$ & $12.92 \pm 7.63$ & $13.82 \pm 8.80$ & 0.3741 \\
Pro-ANP $(\mathrm{nmol} / \mathrm{L})$ & $4.48 \pm 4.53$ & $5.30 \pm 4.26$ & 0.2629 \\
hs-CRP $(\mathrm{ng} / \mathrm{mL})$ & $1.69 \pm 2.67$ & $6.33 \pm 14.59$ & 0.0961 \\
Time to recurrence & $8.67 \pm 4.16$ & $85.5 \pm 134.71$ & 0.0062 \\
(days) & &
\end{tabular}

LA: left atrium, EF: ejection fraction, SEC: spontaneous echo contrast, J final: final CV energy (J), IRAF: immediate recurrence of AF after CV, AAD: anti-arrhythmic drug, APC: atrial premature contractions, MMP-9: matrix metalloproteinase-9, SDF-1 $\alpha$ : stromal cell derived factor- $1 \alpha$, TGF- $\beta$ : transforming growth factor- $\beta$, ANP: atrial natriuretic peptide, hsCRP: high sensitive- $C$ reactive protein, CV: cardioversion, AF: atrial fibrillation

ence rate of AF after successful CV were not affected by LA size. Although the serological parameters were not different between the two groups, MMP-9 (139.6 $\pm 49.97 \mathrm{ng} / \mathrm{mL}$ vs. $107.78 \pm 65.15 \mathrm{ng} / \mathrm{mL}, \mathrm{p}=0.0285)$ and SDF- $1 \alpha(3.76 \pm 1.26 \mathrm{ng} / \mathrm{mL}$ vs. $3.24 \pm 0.99 \mathrm{ng} / \mathrm{mL}$, $\mathrm{p}=0.0261)$ were significantly higher in patients with LA $\geq 48 \mathrm{~mm}$ than in those with LA $<48 \mathrm{~mm}$.

\section{Discussion}

In the present study, we prospectively explored predictors for failure of $\mathrm{CV}$ and recurrence of AF after sys- temic electrical CV. We found that post-CV recurrence of AF commonly occurred in patients aged $>60$ years and low SDF- $1 \alpha$. High plasma levels of TGF- $\beta$ predicted failure of electrical CV. Pre-determination of predictors for failure of $\mathrm{CV}$ or recurrence of $\mathrm{AF}$ after successful CV might be useful for clinical decisions on rhythm control strategies and for increasing our understanding of the pathophysiology of AF.

\section{Serological factors predicting atrial fibrillation re- currence after cardioversion}

In this study, a low plasma level of SDF- $1 \alpha$ was an independent risk factor for AF recurrence after successful CV. The chemokine SDF- $1 \alpha$ has been shown to play a key role in hematopoietic or endothelial progenitor cell trafficking in the myocardial ischemia model, ${ }^{13-15)}$ and the non-ischemic titrated cardiac injury model during catheter ablation of AF ${ }^{16)}$ However, the role of SDF- $1 \alpha$ has been poorly explored in the pathophysiology of AF. Goette et al. ${ }^{17)}$ report that SDF- $1 \alpha$ levels are higher in PeAF than PAF or controls, and SDF- $1 \alpha$ plays some role in the restitution of hematopoietic progenitor cells after failed CV. The reason for the high recurrence of $\mathrm{AF}$ in patients with low plasma levels of SDF- $1 \alpha$ remains to be studied. Although it has been reported that high levels of hs-CRP are associated with an increased risk of recurrence of $A F,{ }^{1218)}$ our data and data of Conway et al. ${ }^{19)}$ failed to prove its predictive value in the clinic. The plasma level of hs-CRP may be associated with the permanence of AF related to systemic inflammation or prothrombotic status. ${ }^{20)}$

\section{Left atrium size and recurrence of atrial fibrillation after cardioversion}

The pathophysiology of AF is heterogeneous, and, like heart failure, includes various kinds of heart disease. ${ }^{21)}$ Like the diversity of AF pathophysiology, the factors related to failed $\mathrm{CV}$ or recurrence after successful CV might be widespread. An enlarged LA may reflect the degree of structural remodeling and LA pres- 
sure, and is one of the predictors for recurrence after RFCA of $\mathrm{AF}^{22)}$ However, LA diameter was not related to the failure of $\mathrm{CV}$ or recurrence of $\mathrm{AF}$ in this study or in other previous studies. ${ }^{1023)}$ With this in mind, one may ask why the meaning of LA diameter is different after electrical CV and RFCA. First, anti-arrhythmic drugs were maintained after $\mathrm{CV}$, but stopped within the 3rd month after RFCA in most institutes. ${ }^{22)}$ Second, CV does not change atrial critical mass, but RFCA reduces it, which contains multiple reentries. ${ }^{21)}$ Third, the risk of recurrence after AF ablation is high in patients with an enlarged LA because of the potential conduction gap on the long distance of linear ablation or non-pulmonary vein foci. ${ }^{25)}$ Fourth, patient selection bias also contributes. In contrast, the mean LA diameter was $45.5 \mathrm{~mm}$ in this study, whereas LA dimensions $>65 \mathrm{~mm}$ have been reported to be associated with $\mathrm{AF}$ recurrence after $\mathrm{CV}{ }^{24)}$ We previously reported that poor mechanical reserve of the LA appendage predicts $\mathrm{AF}$ recurrence after $\mathrm{CV},{ }^{11)}$ and prolonged atrial stunning after electrical $\mathrm{CV}$ is also related to poor clinical outcomes. ${ }^{26)}$ Therefore, mechanical function of the atria may be more important in clinical outcomes after CV than morphological changes in the atria.

\section{The roles of upstream therapy}

Although approximately $50 \%$ of patients who are successfully cardioverted initially experience AF recurrence within the first month after $\mathrm{CV}^{5 / 6)}$ anti-arrhythmic drugs $^{24)}$ and upstream medical therapy are effective in preventing this. Nakashima et al. ${ }^{27)}$ first suggested the potential role of angiotensin II inhibitors for preventing atrial electrical and structural remodeling, and $\mathrm{Ma}-$ drid et al. ${ }^{28)}$ proved its effect in a prospective randomized clinical study in patients with AF after electrical CV. ACE inhibitors ${ }^{29)}$ and statins ${ }^{30)}$ also play roles in the inhibition of $\mathrm{AF}$ recurrence after $\mathrm{CV}$. These upstream therapies may reduce the recurrence rate of $\mathrm{AF}$ after electrical CV by preventing atrial structural remodeling.

\section{Limitations}

The patients included in this study were a highly selected group chosen for their rhythm control; and the number of patients was limited. The exclusion of patients with large atria (bigger than $55 \mathrm{~mm}$ ) may influence the outcomes related to LA size. The peripheral blood samples may only partially reflect the remote process in the atria. Although we used anti-arrhythmic drugs in all patients before and after $\mathrm{CV}$, the proportion taking amiodarone was $60.5 \%$. In this study, mean age was higher in patients with recurrence after $\mathrm{CV}$, and old age with low regenerating power may partially affect the low plasma level of SDF- $1 \alpha$. However, the low plasma level of SDF- $1 \alpha$ was still a statistically significant predictor for $\mathrm{AF}$ recurrence even after adjustment for age by Cox regression analysis \{hazard ratio (HR) 0.443 , CI: $0.245-0.803, p=0.007\}$. Although SDF- $1 \alpha$ has been known to be related to stem cell homing and inflammatory processes, the mechanism underlying it effect on the recurrence of $\mathrm{AF}$ is beyond our purpose and remains to be studied.

\section{Conclusion}

A high level of TGF- $\beta$ was associated with failed CV. Post-CV recurrence was more common in patients aged $>60$ and low SDF- $1 \alpha$ levels. However, LA size did not predict recurrence after $\mathrm{CV}$. These predictors for $\mathrm{AF}$ recurrence after $\mathrm{CV}$ might provide additional information in clinical decisions for rhythm vs. rate control and RFCA vs. repeated CV, in addition to increasing our understanding of the pathophysiology of AF.

\section{Acknowledgments}

This work was supported by a The Korean Society of Circulation Industry-University Cooperation Grant to H-N Pak.

\section{REFERENCES}

1) Benjamin EJ, Wolf PA, D'Agostino RB, Silbershatz H, Kannel WB, Levy D. Impact of atrial fibrillation on the risk of death: the Framingham Heart Study. Circulation 1998;98:946-52.

2) Corley SD, Epstein AE, DiMarco JP, et al. Relationships between sinus rhythm, treatment, and survival in the Atrial Fibrillation Follow-Up Investigation of Rhythm Management (AFFIRM) Study. Circulation 2004;109:1509-13.

3) Roy D, Talajic M, Dorian P, et al. Amiodarone to prevent recurrence of atrial fibrillation. Canadian Trial of Atrial Fibrillation Investigators. N Engl J Med 2000;342:913-20.

4) Singh BN, Singh SN, Reda DJ, et al. Amiodarone versus sotalol for atrial fibrillation. $N$ Engl J Med 2005;352:1861-72.

5) Wyse DG, Waldo AL, DiMarco JP, et al. A comparison of rate control and rhythm control in patients with atrial fibrillation. $N$ Engl J Med 2002;347:1825-33.

6) van Gelder IC, Hagens VE, Bosker HA, et al. A comparison of rate control and rhythm control in patients with recurrent persistent atrial fibrillation. $N$ Engl J Med 2002;347:1834-40.

7) Hwang GS, Kim YH, Lee HS, et al. Electrical remodeling in human atrial fibrillation influences post-cardioversion atrial mechanical dysfunction and early relapse. Korean Circ J 1999;29: 788-95.

8) Goette A, Honeycutt C, Langberg JJ. Electrical remodeling in atrial fibrillation: time course and mechanisms. Circulation 1996; 94:2968-74.

9) Ausma J, Wijffels M, Thone F, Wouters L, Allessie M, Borgers M. Structural changes of atrial myocardium due to sustained atrial fibrillation in the goat. Circulation 1997;96:3157-63.

10) Park MY, Shim WJ, Shin SH, et al. Structural and functional changes of heart after cardioversion of atrial fibrillation. Korean Circ J 2003;33:918-27.

11) Park MY, Shin SH, Oh WJ, et al. Prognostic implication of the left atrial appendage mechanical reserve after cardioversion of atrial fibrillation. Circ J 2008; 72:256-61.

12) Malouf JF, Kanagala R, Al Atawi FO, et al. High sensitivity $C$ reactive protein: a novel predictor for recurrence of atrial fibrillation after successful cardioversion. J Am Coll Cardiol 2005; 46: 1284-7.

13) Peled A, Petit I, Kollet O, et al. Dependence of human stem cell 
engraftment and repopulation of NOD/SCID mice on CXCR4. Science 1999;283:845-8.

14) $\mathrm{Kim} \mathrm{CH}$, Broxmeyer HE. In vitro behavior of hematopoietic progenitor cells under the influence of chemoattractants: stromal cell-derived factor-1, steel factor, and the bone marrow environment. Blood 1998;91:100-10.

15) Askari AT, Unzek S, Popovic ZB, et al. Effect of stromal-cell-derived factor 1 on stem-cell homing and tissue regeneration in ischaemic cardiomyopathy. Lancet 2003;362:697-703.

16) Kim SK, Pak HN, Park JH, et al. Non-ischaemic titrated cardiac injury caused by radiofrequency catheter ablation of atrial fibrillation mobilizes CD34-positive mononuclear cells by non-stromal cell-derived factor-1 alpha mechanism. Europace 2009;11: 1024-31.

17) Goette A, Jentsch-Ullrich K, Lendeckel U, et al. Effect of atrial fibrillation on hematopoietic progenitor cells: a novel pathophysiological role of the atrial natriuretic peptide? Circulation 2003; 108:2446-9.

18) Kallergis EM, Manios EG, Kanoupakis EM, et al. The role of the post-cardioversion time course of hs-CRP levels in clarifying the relationship between inflammation and persistence of atrial fibrillation. Heart 2008;94:200-4.

19) Conway DS, Buggins P, Hughes E, Lip GY. Predictive value of indexes of inflammation and hypercoagulability on success of cardioversion of persistent atrial fibrillation. Am J Cardiol 2004; 94:508-10.

20) Conway DS, Buggins P, Hughes E, Lip GY. Relationship of interleukin-6 and C-reactive protein to the prothrombotic state in chronic atrial fibrillation. J Am Coll Cardiol 2004;43:2075-82.

21) Nattel S, Opie LH. Controversies in atrial fibrillation. Lancet 2006;367:262-72.

22) Shin SH, Park MY, Oh WJ, et al. Left atrial volume is a predictor of atrial fibrillation recurrence after catheter ablation. $\mathrm{J} \mathrm{Am}$
Soc Echocardiogr 2008;21:697-702.

23) Duytschaever M, Haerynck F, Tavernier R, Jordaens L. Factors influencing long term persistence of sinus rhythm after a first electrical cardioversion for atrial fibrillation. Pacing Clin Electrophysiol 1998;21:284-7.

24) Hyon MS, Lee SH, Cho SJ, Park SH, Kim MA. Electrical cardioversion of chronic nonvalvular atrial fibrillation under transesophageal echocardiographic guidance. Korean Circ J 1997;27: 488-500.

25) Pak HN, Hwang C, Lim HE, Kim JW, Lee HS, Kim YH. Electroanatomic characteristics of atrial premature beats triggering atrial fibrillation in patients with persistent versus paroxysmal atrial fibrillation. J Cardiovasc Electrophysiol 2006; 17:818-24.

26) Climent V, Marin F, Monmeneu JV, Garcia de Burgos F, Sogorb F. Atrial stunning as predictor of early relapse into atrial fibrillation after cardioversion. Int J Cardiol 2006; 110:427-8.

27) Nakashima H, Kumagai K, Urata H, Gondo N, Ideishi M, Arakawa K. Angiotensin II antagonist prevents electrical remodeling in atrial fibrillation. Circulation 2000;101:2612-7.

28) Madrid AH, Bueno MG, Rebollo JM, et al. Use of irbesartan to maintain sinus rhythm in patients with long-lasting persistent atrial fibrillation: a prospective and randomized study. Circulation 2002;106:331-6.

29) Yin Y, Dalal D, Liu Z, et al. Prospective randomized study comparing amiodarone vs. amiodarone plus losartan vs. amiodarone plus perindopril for the prevention of atrial fibrillation recurrence in patients with lone paroxysmal atrial fibrillation. Eur Heart $J$ 2006; 27: 1841-6.

30) Fauchier L, Pierre B, de Labriolle A, Grimard C, Zannad N, Babuty D. Antiarrhythmic effect of statin therapy and atrial fibrillation a meta-analysis of randomized controlled trials. J Am Coll Cardiol 2008;51:828-35. 